\title{
WHY HAS IRAN'S FAMILY PLANNING POLICY BEEN SO SUCCESSFUL? POLITICAL, DEMOGRAPHIC, SOCIO-ECONOMIC AND CULTURAL-GEOGRAPHICAL UNDERPINNINGS OF A DRAMATIC FERTILITY TRANSITION
}

\author{
Maryam ALAEDDINI ${ }^{1} \bullet$ David LÓPEZ-CARR ${ }^{2}$ \\ ${ }^{1}$ Iranian Ministry of Health \\ Teheran, Iran \\ maryam.alaeddini@gmail.com \\ ${ }^{2}$ UC Santa Barbara \\ Department of Geography \\ 4840 Ellison Hall, Santa Barbara, CA 93106-4060, USA \\ david.lopez-carr@ucsb.edu
}

\begin{abstract}
A solid international legal framework for family planning supports national family planning programs. Yet it is not by itself a program guarantee, especially among Muslim nations, many of which have stalled FP transitions and weak or absent government assistance for FP programs. The success of Iran's family planning program, therefore, is all the more noteworthy. Since its establishment in 1993, it has been one of the most successful state family planning (FP) programs in the world, having reduced the national annual growth rate from $2.7 \%$ in the late 1960 s to little over $1 \%$ currently. This paper explores international and national legal, institutional, demographic, and cultural-geographical influences that may have contributed to its results.
\end{abstract}

Key-words: Iran, post-revolution, Islam, Shariat, family planning, fertility, population geography, urbanization, education, religion, globalization, cultural geography.

\section{Introduction}

Iran's total fertility, i. e. the average number of births per woman, decreased from 6 in 1986 to 1.9 in 2003. It has remained constant since (Word Bank Indicators Website ${ }^{1}$ ). The population growth rate dropped from 3.2 percent to 1.3 percent, a rate only slightly higher than that of Switzerland in 2011. This unusually rapid fertility transition has been one of the most inspiring models for countries wishing to reduce population growth, to improve maternal and child health, and to empower women. What were the main causes for this nation-wide achievement?

\footnotetext{
${ }^{1}$ http://data.worldbank.org/indicator
} 
Some biological and behavioral factors, such as the use of contraception, directly affect the fertility rate. There are, however, socioeconomic, cultural and environmental variables that indirectly underlie the change in the fertility rate. For instance, studies indicate that fertility is usually higher in rural than in urban areas, and higher in households with low incomes (Bongaarts 1978; Merrick 2001; Carr et al. 2006). Moreover, it is well-established that quality and quantity of women's education are highly predictive determinants of the fertility rate (e.g. Caldwell 1980). Religion and culture can also be influential (Reichenbach 2009). Our aim in this paper is to discuss and evaluate various underlying fertility determinants that were present in Iran's FP. We examine the extent to which several of these socioeconomic, cultural and environmental determinants may have enabled Iran's decline in fertility.

Iran's first Family Planning policy was introduced in 1967 under Shah Reza Pahlavi to improve the status of women by reforming divorce laws, encouraging female employment, and acknowledging family planning as a human right. But the program had little success due to a low literacy rate, general apprehension, and other cultural obstacles. At that time, the average growth rate was $2.7 \%$, similar to other developing countries lacking widespread family planning methods.

The FP policy was reversed in 1979 at the beginning of the Islamic Revolution (Larsen 2001). The government at the time implemented legal changes in marriage laws, including the reduction of the age of marriage, elimination of limitations on polygamy, provision of financial support for new couples, and provision of land to families with more than five children (Moinifar 2007). At that time, FP programs were viewed by government sources as a western imperialist influence over the country. Following the outbreak of the war between Iran and Iraq (1980-1988), Ayatollah Khomeini urged people to have larger families to support a "soldiers for Islam" increase to "an army of 20 millions". According to United Nations data on Iran, the population doubled from 27 million in 1968 to 55 million in 1988. In the post war period, Iran's rapid population growth was considered by many a crucial obstacle to reconstructing the country. In response, Ayatollah Khomeini reopened discussions on the subject of FP (Larsen 2001).

The founder of the I.R. consented to FP based on the following terms:

- Consensus of both spouses on the use of contraceptives

- Contraceptives should not have significant side effects

- Reversibility (allowing for the possibility of a future pregnancy)

- The method used should not be accompanied with sin (e.g., same sex service providers should be consulted) (Malekafzali 2004, p. 247)².

By December 1989, Iran had revived its national FP. The main goal was to limit family size to three children by encouraging women to wait three to four years between pregnancies, and by discouraging child bearing for women younger than 18 or older than 35. In May 1993, the Iranian government passed a national FP law in which it encouraged couples to have fewer children by restricting maternity leave benefits after three children. To accomplish this, there was significant involvement of the following ministries: Education; Culture and Higher Education; Health and Medical Education, and Islamic Culture and Guidance. Also, the Islamic Republic of Iran Broadcasting Corporation cooperated with the abovementioned ministries in raising public awareness on the enacted FP law (Lar-

\footnotetext{
2 It is worth mentioning here that abortion is not defined as a population contraceptive tool and is prohibited in the Islamic Republic except under certain conditions.
} 
sen 2001). The startling results of the national FP program are, despite rapid transitions in South Asia, northern Africa, and Latin America, a global anomaly and merit analysis. We argue that several factors were critical in supporting the success of Iran's FP program.

First, as we will explain in greater detail in section II, the international law provides a supportive environment for Iran to implement its FP program.

Second, as we will detail in section III, different parts of the government collaborated to provide a legal context aimed at increasing public awareness, providing incentives, and increasing accessibility to contraceptive tools, especially in rural areas.

Third, as discussed in section IV, rapid economic development during the period had several direct and, perhaps more importantly, indirect influences on fertility. As the cost of child rearing increased so did both the average age of women giving birth for the first time and the supply of, and demand for, contraceptives. At this time, the Iranian society was experiencing urbanization, and socio-cultural change, both supportive of a lower fertility rate.

Fourth, a significant and relatively early process of urbanization and industrialization which followed the revolution considerably narrowed the urban-rural gap in health care access (section V. A).

Fifth, Iran experienced a rapid improvement in women's education after the revolution (section V. B), a critical independent determinant of fertility globally.

Sixth, we argue that the impact of globalization on local cultural geographies likely increased the use of contraceptives (section V. C).

Finally, as we will discuss in section $\mathrm{VI}$, contrary to what has occurred in many parts of the world, rather than hinder FP adoption, religion appears to have played a mostly supportive role in Iran's FP transition, with many religious leaders, including Ayatollah Khomeini, actively supporting the program.

\section{Underpinnings of Iran's Fertility Transition}

\section{International law}

From the perspective of international law, family planning programs are closely related to reproductive rights and women's rights. A key issue regarding reproductive rights is autonomy. Its essential features are respect, dignity and control. The underlying tenet is that humans, in general, and women in particular, should be able to control and make decisions about their reproductive lives. Rather than isolating reproductive rights, this holistic view incorporates these rights into all aspects of life. (Freedman and Isaacs 1993).

Population movements have played an important role in shaping reproductive rights discourse. According to some theories of development, population growth is a serious obstacle to development (e. g. Coale 1986; Hoover 1958). The World Bank is a strong proponent of population programs. "The Bank views population assistance as its highest priority in Africa" (World Bank, World Development Report 1986). However, one might wonder whether population movements oppose reproductive rights. The Chinese one child per family policy may be an instance where the population program violates reproductive rights. However, when population programs are more subtle, the issue is less clear. A key to population programs is the provision of incentives and disincentives. But are incentives inherently coercive? Perhaps not. It seems that there is a difference between population 
policies addressing health concerns, and those addressing merely demographic ones. Population programs that arise from health concerns may have a better chance of finding wider political embrace.

International laws regarding reproductive health have been shaped by national and international women's rights and population movements. Traditionally, international laW's main concern was relations among nation-states. After World War II and following the establishment of the United Nations, a big change occurred in the scope of international law. The United Nations, as an independent entity in international law, actively promoted universal rights in this new world order. Moreover, the emergence and progress of the right to reproductive choice is due to a series of international and non-governmental organizations and conferences working to define reproductive rights and specify their implications.

In 1968, 20 years after the Universal Declaration of Human Rights, human reproduction received international legal attention at the International Human Rights Conference in Tehran. One of the resolutions in Tehran was that "parents have a basic human right to decide freely and responsibly on the number and spacing of their children and a right to adequate education and information in this respect" (UN 1968). Since then, the Tehran Declaration has been the starting point for the UN member nations and nongovernmental organizations in clarifying the details of a person's reproductive rights.

According to many development theories in the 1960s (e.g. Hoover 1958), uncurbed population growth in developing countries such as China and India would lead to environmental destruction and social problems. Because overpopulated developing countries had discouraging policies toward contraception, these problems were even more serious. To the delegates in Tehran, overpopulation was regarded as a threat to humankind. The Tehran Declaration increased pressure on developing countries that had resisted the use of contraceptives within their borders, to address overpopulation (see Freedman and Isaacs 1993).

At the time of the International population conference in Mexico City (1984), poor nations came to a greater realization of the severity of rapid population growth and infant and child mortality. The hope for a new economic international system had paled due to developing national debts to the IMF and World Bank. OPEC was also less inclined to assist the developing countries, compared to the 1970s. In the recommendations of the conference, governments should "as a matter of urgency" make family planning services "universally available" (UN 1984).

In 1994, the International Conference on Population and Development (ICPD) was held in Cairo. The ICPD defined a new population policy which gave prominence to reproductive health and women's empowerment. It decreased the demographic focus in population policy and increased the economic, human rights, and socio-political foci. The Program for Action was tasked with formulating the consensus position on population and development for the next twenty years (Mcintosh and Finkle 1995).The Program for Action asks governments to address such issues as reduction of maternal mortality, prevention and treatment of sexually transmitted diseases, including HIV, prevention and treatment of unsafe abortions, and the empowerment of women. According to the new model, programs that act directly on fertility are often coercive and abusive of women's rights to choose the number and timing of their children. Rather, the international community needs to adopt programs that empower women through increasing education, 
providing jobs, lightening domestic responsibility, and improving social status. Family planning should be only one component in a comprehensive plan of reproductive health.

The I.R Iran endorsed the Program for Action and, for the most part, it committed itself to implementing policies recommended by the program. Five years after ICPD the Iranian delegate to the EU stated: "I would like to reiterate that the Government of the Islamic Republic of Iran is highly committed to the recommendations of the ICPD-POA and, with UNFPA active support and assistance, has been quite successful in their implementation. Of note: the budget for the implementation of RH/FP program recommendations was continuously increased, reaching a total of 12 million dollars" (UN 1999).

International legal context for family planning supports, but does not guarantee, a national family planning program. Many Muslim nations and weak or absent government assistance for FP programs have stalled FP transitions.

Why then was Iran's implementation of its program successful? International law and policy appear to have been buttressed by a state legal context that included the earnest application of rural family planning programs, and a suitable cultural geographical context which included relatively early and significant industrialization and urbanization, and local cultural elements - including ways in which Iran embraced globalization, education and the support of religion. Next we discuss the state legal context.

\section{State legal context}

On the one hand, the effective implementation of the program by the State provides us with a top-down explanation for the success of the program. On the other hand, the social and cultural context in which the program was implemented led to high public participation. Without high participation from the public FP could not have been as successful as it was. Cultural globalization, urbanization, and increases in women's literacy are part of the social and cultural context in which FP was implemented but these are only as relevant as the state allows.

In this section, we will discuss the role of the State in the program. It is worth noting that all governments after the revolution adopted the same policy toward FP. The implementation of FP was never a matter of dispute among political parties and governments until 2011. We discuss first the State policies and then proceed to explain the role of institutions. Moreover, health clinics, which we will address at the end of the section, played a crucial role in implementation of the program in rural areas.

\section{Policies}

In 1990, the Council of Ministers approved a Birth Limitation Council to be implemented through collaboration among various ministries and departments. Its goals were to achieve the following (Aghajanian 1998, p. 12):

1. Provide educational programs for the public on population issues

2. Provide various high quality family planning methods for married couples

3. Carry out research on different aspects of family planning delivery and population policy.

The objectives of the Birth Limitation Council were to decrease the birth rate, population growth rate and total fertility rate. 


\section{Supplementary Policies}

Following the acceptance of, and consensus on, family planning by religious and political leaders, the government envisioned the following guidelines to implement the plan: provide face-to-face education for at-risk groups to promote family planning; integrate family planning and population control in other national development programs; enhance the health provider's skills by training and retraining, especially in the area of the new methods. The family planning system should be integrated with the national primary health care system to provide educational materials on population and family planning for high school and university curricula. It should collaborate closely with international organizations in order to learn from their experiences and share the lessons learned from Iran's experience with others, especially with Islamic nations (Malekafzali 2004, p. 248).

\section{Collaborative Arrangements among Ministries}

From the perspective of institutional theory, social, economic, religious and political institutions interact with population policy changes, and with individual attitudes in response to these policies (McNicoll 1980, 1985, 1994; Greenhalgh 1988). The revolution made abrupt changes in the existing institutions. After the Islamic revolution, a revolutionary Jihad movement formed to develop rural areas. It's worth noting that 'Jihad' does not merely mean holy war; its original meaning is "struggle". The revolutionary Jihad movement was a non-military movement with a religious motivation to develop underdeveloped areas. The formation of a revolutionary Jihad movement expedited the process of development in rural areas.

Another institutional change took place with the health clinics. Health clinics had existed before the revolution but after the revolution the ministry of health expanded its activities by providing more human resources and facilities. Another important institutional change was the acknowledgment of the role of women in communities. Although participation of women in the labor force did not increase, nevertheless, as Moghadam (1998) argues, after the revolution women were not driven out of the work force.

A further critical aspect of Iran's family planning was the creation of a legal framework of collaborative cooperation among various ministries in executing the program. The legal framework was enacted by the First Economic, Social and Cultural Development Plan of the Islamic Republic of Iran sanctioned in 1989. Following this enactment, the Council of Ministers adopted it for each ministry. These tasks directly or indirectly relate to family planning. The following are the tasks that each ministry was charged to undertake in FP development (Aghajanian 1998, p. 16).

Ministry of Education

I. Integrate population education materials in high school textbooks in order to raise awareness, especially among girls, of high fertility.

II. Increase literacy among all socio-economic ages, especially through adult education. Also, increase enrollment for rural female school-age population.

Ministry of Islamic Culture and Guidance

I. Produce more programs for social and community-based involvement of women.

II. Create more programs to raise public awareness on the importance of reducing population growth rate and the disadvantages caused by a high growth rate. 


\section{Ministry of Higher Education}

I. Incorporate more demography and population courses into the core university syllabi.

II. Increase women in teacher training programs, and provide incentives to work in remote and underdeveloped areas.

III. Increase research on population and family planning in universities.

\section{Civil Registration Organization}

I. Implement an effective system to register vital events such as births and death, especially in less developed areas (this helped improve program evaluation).

\section{Health Clinics in Rural Areas}

The development of rural health clinics was important for the success of FP programs in rural areas. In 1972, the pre-revolution regime estimated that 2,450 clinics in rural areas would be enough to "provide good access". However, the Islamic regime aimed to establish 18,000 rural clinics to empower the FP program (Moore 2007, p. 40). Moreover, the rural clinics built on a rapidly expanding rural health infrastructure, known as Health Network System. As a result, when the FP program was added to the Health Network System, it was regarded as a part of the rural development program and not an attempt to limit rural population growth. Each health clinic serves about 1500 individuals with at least two staff, at least one of whom is a woman. Staff members are usually recruited locally and trained for two years in primary health care delivery (Salehi-Isfahani et al. 2010, p. 4).

Figure 1 shows the health clinics by year of establishment (Salehi-Isfahani et al. 2010, p. 5). As Figure 1 shows, in 1985, when the law for mandating a Health Network System came into effect, the pace of construction of health clinics increased. By 2005, the program covered about $90 \%$ of the rural population with about 16,560 health clinics. The health clinics provided active (as opposed to passive) service delivery. As Salehi-Isfahani et al. (2010, p. 2) indicate, active service delivery considerably helped the success of FP program. Passive delivery depends on initiatives of the individuals. However, in active service delivery, the health clinic made sure that each woman had access. For example, in passive service delivery, if a woman on the pill ran out of birth control, she could go to a nearby town to purchase birth control pills or wait for the next mobile unit's visit, which might take up to a month. However, in active service delivery, the health worker would

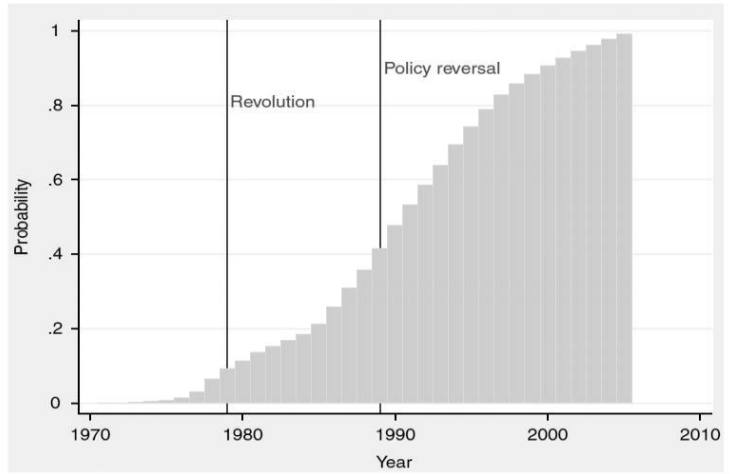

Fig. 1. The distribution of health houses clinics in rural areas (Salehi-Isfahani et al. 2010) 
make sure that she had her monthly supply. The information on each individual would be kept in huge databases. In the paternalistic and conservative rural culture of Iran, the difference between active and passive service delivery can represent the difference between having, or not having, access to birth control technology.

\section{Economic context}

Many argue that the drastic fertility reduction in Eastern and Central Europe during the 1990s should be explained mainly in terms of economic factors (e. g. Kohler and Kohler 2002; Rutkevich 1996; Witte and Wagner 1995) such as falling income level, a rise in economic and labor-market uncertainty etc. The rise in household expenses and cost of raising children, together with uncertainty about employment, may force parents to reconsider the number of children they have. However, it seems unlikely that the fertility rate reduction in Iran can be explained merely in terms of economic factors.

While fertility rate, was consistently dropping from 6 in 1986 to 1.9 in 2003 (World Bank Indicators), as Figure 2 shows, we observe a smooth increase in GDP growth facilitated by a rapid increase in oil investments (Esfahani and Pesaran 2009, p. 10). In 1995, due to a sudden change in exchange rate we observe a very high inflation rate. However, if we set aside the unusual increase of inflation in 1995, we observe that the price of inflation has a smooth decreasing trend. There was also no significant change in male or female unemployment from 1989 to 2008 (World Bank Indicator Website). So we may say that there is no significant increase in labour-market uncertainty. As we will see in the next section, due to urbanization, we also note improvement in the standard of living during this period.

The female mean age at marriage increased from 19.9 in 1986 to 22 in $2004^{3}$. However, the increase in the female marriage age may not be due to purely economic factors

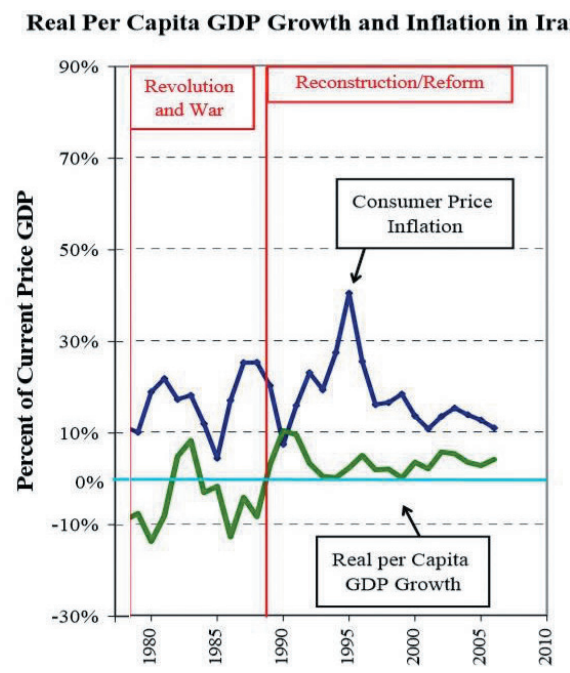

Fig. 2. GDP growth and Inflation in Iran (1980-2010) (Esfahani and Pesaran 2009)

\footnotetext{
${ }^{3}$ From the website of national organization for civil registration. (http://www.sabteahval.ir/Upload/Modules/Contents/asset99/AmarHayati/et--83.pdf)
} 
for we don't observe a parallel rapid increase in men's marriage age. Moreover, there are other factors contributing to this phenomenon. Some scholars have attributed the increase in women's marriage age to socio-cultural change after the revolution, women's education, urbanization, and access to the means of communication (Mahmoudain 2005). Other studies show that a result of the baby boom following the revolution was half a million more women than men at the age of marriage (Jafari-Mojdehi 2003). Perhaps in addition to serving as a direct cause of fertility decline in Iran, as observed in other contexts with rapid fertility decline such as rural Mesoamerica in recent years (Davis and López-Carr 2010; Carr 2007; Sutherland et al. 2004), rapid economic growth may have facilitated several other cultural socio-economic and demographic factors all related to decreasing fertility in post-revolutionary Iran. We now discuss this larger cultural and religious context in relation to falling fertility in Iran.

\section{Cultural context}

\section{Industrialization and Urbanization}

The implementation of FP in Iran did not take place in a vacuum. Several crucial social and historical events appear to have facilitated FP implementation. If we take a closer look at the groups and agenda involving the revolution and post revolution, we observe two main uniting themes. First, shared opposition to the Shah and all political organizations created by him. Second, a rather simplistic belief that Iran had all the natural and human resources for rapid socioeconomic development and modernization achieved by Westerners. Even the conservative clerics who quickly took over the power left by the sudden disintegration of the old regime were in favor of these popular ideals.

Table 1. Socioeconomic indicators for Iran

\begin{tabular}{|l|r|c|c|c|c|c|c|}
\hline & $\mathbf{1 9 7 6}$ & $\mathbf{1 9 8 6}$ & $\mathbf{1 9 9 6}$ & $\mathbf{1 9 9 8}$ & $\mathbf{2 0 0 3}$ & $\mathbf{2 0 0 8}$ & $\mathbf{2 0 1 1}$ \\
\hline Maternal mortality per 100,000 births & 277.0 & 140.0 & 37 & 60 & $\mathbf{4}$ & 31 & 25 \\
Life expectancy & 58.0 & 66.0 & 67 & 70 & 72 & 74 & 75 \\
Adult Literacy Rate (\%) & 46.9 & 61.3 & 73 & & 77 & 85 & 84 \\
Youth literacy (\% of people ages 15-24) & & 75.0 & 93 & & 93 & 99 & 98 \\
Urbanization (\%) & 47.0 & 54.6 & 61.3 & 63 & 66 & 68 & 69 \\
\hline
\end{tabular}

Source: World Bank Development Indicators.

Table 2. Percent access to amenities by urban and rural areas

\begin{tabular}{|l|c|c|c|c|}
\hline \multirow{2}{*}{} & \multicolumn{2}{|c|}{1977} & \multicolumn{2}{c|}{1997} \\
\cline { 2 - 5 } & Urban & Rural & Urban & Rural \\
\hline Electricity & 91 & 15 & 99 & 92 \\
Piped Water & 80 & 12 & 98 & 12 \\
Telephone & 16 & 1 & 53 & 60 \\
Radio & 78 & 52 & 78 & 69 \\
TV & 52 & 2.4 & 93 & 78 \\
\hline
\end{tabular}

Source: Mehyar and Tajidini (1998). 
According to Abbasi-Shavazi et al. (2002, p. 15), almost all of the revolutionaries endorsed development and modernization by raising the level of education of all citizens, improving their health status, and meeting their basic needs by means of the oil glut of the early 1970s. In his first speech on his return to Iran, Ayatollah Khomeini publicly announced that the new regime would not only provide all social services for free, but also would abolish all existing taxes and arrange for the regular disbursement of oil revenues among the people. Shortly after the revolution, clerics in charge of the Islamic Housing Foundation announced that the government would give free land and interest-free loans to build houses in Tehran. It's believed that this is one of the reasons behind the tremendous increase in migration to Tehran during the first year after the revolution (Abbasi-Shavazi et al. 2002, p. 15).

The constitution of the Islamic republic of Iran envisages a welfare state. It anticipates many of the ideals currently advocated by the United Nations as part of its new paradigm of Sustainable Human Development (Mehryar 1997). During the eight-year Iran-Iraq war, it seemed reasonable that the government of the IR would devote fewer resources to the social development programs and enshrined priorities in the constitution. However, a recent study of basic social services, i.e. primary education and health, showed that even at the height of the war, the government invested a sizeable proportion of its annual budget in social services (Mehryar et al. 1999).

Moreover, the IR of Iran was making a constant effort to target the neglected rural and marginalized classes of society. Due to investment in social development and services there have been significant changes in modernization and living standards. Table 1 and 2 demonstrate that both urban and rural populations experienced a higher standard of living after the revolution.

According to Table 1 there was a substantial fall in both infant and maternal mortality rates and a rise in life expectancy. Adult literacy has risen greatly. Moreover, the urban-rural gap has been considerably narrowed in terms of access to health, education and modern amenities.

\section{Expansion of the Literacy Program}

Women's educational attainment in fertility decline is of great importance. For example, Caldwell proposes several mechanisms through which education is associated with declines in fertility (Caldwell 1980, p. 249).

Table 3 shows a rapid increase in women's literacy after the revolution. As Table 3 suggests after the revolution the number of women with a high school diploma increased by more than $100 \%$. The increase in the number of educated women continued. For example, the ratio of women to men admitted to undergraduate school was .65 in 1996 and 1.67 in 2004. The rise of women's attendance in both primary and higher education is partly due to government investments.

Changes favoring fertility decline also occurred at the household scale. As Abbasi-Shavazi et al. (2002, p. 17) note, the share of educational expenses in total household expenditure remained under 1 per cent for the period 1979-1989 for both urban and rural households. It rose above 1 percent of the total expenses of urban households in 1990 and continued to rise until 1995 up to 2.3 percent of total household expenses. As for rural households, there has been a steady rise in the share of educational expenses in the total household expenses since 1990. 
Table 3. Women's education, comparison between 1976 and 1996 in Iran

\begin{tabular}{|l|c|c|}
\hline & 1976 & 1996 \\
\hline Proportion of girls in primary-level education & 66 per 100 boys & 90 per 100 boys \\
Proportion of girls in secondary-level education & 59 per 100 boys & 81 per 100 boys \\
Proportion of women in higher education & 47 per 100 males & 68 per 100 males \\
Number of non-student women with a secondary school diploma & 447,000 & $2,100,000$ \\
Number of non-student women with tertiary education & 75,000 & 495,000 \\
\hline
\end{tabular}

Source: Abbasi et al. (2002).

\section{Local and Global Culture}

In Iran, there is a nation-wide use of birth control between marriage and the first pregnancy. According to Shahvazi and Morgan (2009), there may be two reasons for this social phenomenon. The first can be called the conjugal marriage explanation in which the use of birth control between marriage and first pregnancy was due to a new form of strong emotional bond between husband and wife and to egalitarian values. The conjugal marriage legitimizes partnership for companionship and intimacy, not solely for procreation. Some believe that the emergence of this new form of marriage was influenced by globalization and westernization in Iran. We should note that although Iran is not an active player in economic globalization, it was by no means isolated from cultural globalization. Goode (1963) argued that "Western ideologies supporting free mate choice and egalitarianism were overwhelmingly attractive to non-Western indigenous young people". And if we take into consideration economic development and industrialization, we observe that these elements give young people freedom from elders and freedom to act in the way they desire. Hand in hand, globalization and industrialization expedited the process of couple-centered egalitarian relationships in Iran.

The second reason that Shahvazi and Morgan (2009) offer for the use of birth control between marriage and first pregnancy is the religious influence. Islam recommends early marriage. Accordingly, the Islamic government of Iran encourages people to marry early by providing resources. The State and its political/religious actors also encourage postponing parenthood with birth control. Postponement of parenthood is, in apart, an economic decision, but a decision also influenced by cultural globalization. Parents, both father and mother, want time for school and work. They want to save money for the future of their children.

Common to both these explanations are cultural globalization and the rise of civil society (Carr and Norman 2008). While global values play an important role in the use of birth control between marriage and the first pregnancy, the religion and local cultural geography are also determinants of the changing population geography of Iran (e.g., Trewartha 1953; Kearns 1993; Price et al 1993).

\section{Religion}

With regard to the religion, one of the most contested issues worldwide is reproductive right. Religions have obstructed reproductive rights at times. Many of the world's religions, particularly Abrahamic religions such as Christianity and Islam, have commands and codes of behavior related to sexuality and reproduction. Abrahamic religions take serious 
stands against non-conservative codes of behavior concerning regulation of marriage, sexuality, gender relations and procreation. Such religions resort to orthodox beliefs for universal and timeless adherence among their followers. The Roman Catholic Church has at times opposed sexuality and reproductive rights (Reichenbach 2009). The attitude of the Catholic Church on the right of family planning was expressed in 1983 in this way: "The spouses have an inalienable right to found a family and to decide on the spacing of births and the number of children to be born, taking into full consideration their duties towards themselves, their children already born, the family and society, in a just hierarchy of values and in accordance with the objective moral order which excludes resource to contraception, sterilization and abortion". The Church has not yet changed its view on this issue (Eriksson 2000, p. 186). Yet, globally we observe that socio-economic factors, ultimately, have trumped religion in FP adoption in Christian-dominated societies.

Unlike Catholicism, Islam has no central hierarchy governing its church. There are different stands on the acceptability of family planning. Among Islamic leaders, reformists argue that there is no prohibition on family planning in the Quran, and no reference in the prophet's writing on the withdrawal method to prevent pregnancy. They conclude that modern contraceptives are permissible. According to the other school of thought, the traditionalists, it is God who plants his seed where he wills. The traditionalists are totally against withdrawal because they consider it tantamount to killing the human seed. However, religious leaders from many Islamic countries have issued fatwa's in favor of family planning since the early 1990s.

While some argue that pro-birth tendencies are inherent in Islam, others think that Islamic beliefs are not responsible for the population growth in many parts of the Muslim world. The Islamic law views marriage as sacred and regards family as an important component of Islamic society. The Quran recommends marriage and procreation to those who are physically and economically capable of raising a family. As opposed to other religions where sexual relations are allowed only for having children, Islam does not view sexual relations exclusively as a means to procreate (Omran 1992).

The Shia, contrary to the Sunni, stress the concept of ijtihad (i.e. independent reasoning) which is the exertion of effort by a trained jurist taking into account all sources of Islamic law to discover a rule for a particular situation. ljtihad is a mechanism to keep Islamic law current with the intellectual, political economic, legal and technological development of a society. In Shia, there is no central authority who can give the ultimate, indisputable ruling for a particular situation. In other words, there is not a hierarchal relation among the clergies. This means that there is decentralization with dissimilarities among various clerics' fatwas on a common issue. As a result of the lack of shared fatwas among clerics on family planning, different fatwas govern the issue (Afshar 1985). Many clerics opine that family planning increases the well-being of Islamic society and that it can be accommodated in Islam. This opinion is supported by the following quote by Aghajanian (1998): "According to the narrations, quotations, Hadis, and verses of holy Quran, the top priority for the Muslim community is the social welfare of the Muslims. Benevolence, virtue and prosperity in life are the first principle(s) of living under the shade of the tremendous tree of religion. This notion can be conceived from every line of Quran narrations and from the quotations from Prophet Mohammad" (Aghajanian 1998).

In general, a new policy is acceptable to Islamic law if it does not violate prohibitions of the Quran and the Prophet's deeds and speeches. A historical review of Islamic juri- 
sprudence reveals that coitus interruptus was allowed in the Prophet Muhammad's time. The companions of the prophet used to practice it. The Prophet came to know about it and did not prohibit them (Mahmood 1977, p. 91).

Family planning is not a new issue in the history of Islam. For instance, the medieval Islamic scientists Avicenna and Razi used an herbal prescription for the prevention of pregnancy. In contemporary times, the first fatwa on family planning in Iran was issued by Ayatollah Bahauddin Mahallati in 1964. The fatwa declares "various methods of pregnancy control are not prohibited by religious laws, as long as their effect is temporary and do not make women sterile" (Apud and Mehryar 2005). It is worth considering that even before Reza Shah there was legalized family planning; it became an issue for religious leaders. In general, the Muslim world had to consider family planning to deal with resource scarcity due to high population growth. Ayatollah Khomeini resisted family planning practices at the beginning of the Iran-Iraq war when soldiers were needed. But afterwards, he accepted it because the country was not capable of dealing with high population growth and its collaterals. In promoting family planning in Iran, the religious leaders played an active role to the extent that FP was endorsed in Friday prayers.

Following the Islamic revolution, the relationship between government and religious power changed. Before the revolution, the religious schools and leaders were financially and structurally independent from the government. The religious leaders mainly opposed the Pahlavi regime due to its anti-religious and pro-western position. After the revolution the religious leaders were in a position to make decisions for the whole nation. With the doctrine of the Guardianship of the Jurist (i. e. Wilayat al Faqih), one of the top religious leaders took over the State's political-religious position. Although the original Shia provided no hierarchy among clerics, the doctrine of the Guardianship of the Jurist (designed by Ayatollah Khomeini) established him in practice as the first religious leader. With the highest political and religious standing, he was in charge of legitimizing the state and government and making all important national decisions.

Hence, when Ayatollah Khomeini did not accept the continuation of the Shah's family planning program, it became ineffective. However, given the original Shia position, people are not required to follow the leader in all religious issues. Rather, they can choose a cleric they believe to be the most knowledgeable on religious issues as their own religious authority. If a religious authority finds an issue in disagreement with the Quran, Prophet's act, speech and behaviors, or consensus among religious community, he can veto the law related to the issue. Thus each religious leader's judgment can potentially affect FP. However, almost no religious authority in Iran found the FP to contravene any of the three main pillars of Islamic law. In sum, it appears that many clerics, including Ayatollah Khomeini, played an important role in the success of FP. Others who were not particularly in favor of FP did not obstruct it.

\section{Discussion and conclusion}

Some authors argue that economic hardship plays a distinctive role in the decrease of Iran's fertility rate (Abbasi-Shavazi 2002, p. 429). However, we find this claim unconvincing for several reasons. On the one hand, the major drop in fertility rate occurs from 1989 to 2003 when we observe a post-war economic development in Iran. On the other hand, 
while there is a severe economic hardship during war time, the fertility rate remains high. Moreover, we observe a dramatic drop in fertility rate from 1989 to 2003 and continuing to 2011, with no serious negative economic event occurring in this period. Economic factors alone can't explain this unusual phenomenon. In this time frame, other phenomena such as significant institutional changes, a noteworthy increase in women's education, and a rather radical cultural change, were unfolding concomitantly. These were likely also critical determinants of the fertility rate. Indeed, perhaps it is more plausible to hold that the aforementioned changes played a bigger role in the decrease in national fertility rate than did economic factors.

The economic hardship may not have been a major contributing factor in Iran's decreasing fertility rate. Yet, the increasing cost of raising children may have had an impact on the drop in fertility rate. But, again, this is supported by an increase in living standards, rapid urbanization, rapid progress in education, and local and global cultural change all amenable to lower fertility rates. The changes in question in this period led some parents to contend that they should raise their children with higher living standards. To that end, and in keeping with other societal changes of this period, women's marriage age shifted upward.

We do not argue that the whole credit of the successful FP should be given to the government. A major point of this paper is that for a State family program to be successful on economic, social, and ethical grounds it needs appropriate contextual support. The State program has a better chance of success when there is support at the grass-roots level. This requires appropriate social, cultural, religious and global foundations.

We are inclined to think that after the war, urban people, especially women, adopted a rather new life style because of globalization, local change in culture, urbanization and significant grassroots support for reformists, which led to the election of a reformist government in 1997. The government's FP program, among other factors, raised the public's awareness of the importance of raising children with higher living standards. On the other hand, FP implementation was facilitated for families by huge material and cultural support from the government. The government's role in rural areas was, we believe, even more important. However, due to a rapid urbanization, the gap in cultural values in rural and urban areas was also decreased. The religion may not have been a major contributing factor to the decrease in Iran's fertility rate but it was important especially in rural areas that it did not hinder the FP program.

The supporting international legal environment should not be overlooked. While I. R. Iran has suffered from its international relations with the global community, the consensus among local authorities and global institutions on the importance of the program helped I. R to become part of the global FP community, and thus had an encouraging impact on local governments.

We believe, therefore, that the success of FP in Iran cannot be explained by a single factor. Many different and interrelating factors help explain the phenomenon in question. We argue that Iran's success in its national FP program was rooted in its implementation within a suitable and fertile international, national, institutional, socio-economic, demographic, and cultural geographical context. Iran pursued its FP when the international community demanded such a program and when a rapid process of urbanization was well underway. Significant progress in women's education after the revolution was an additional critical determinant in decreasing the national fertility rate. While the fertility rate is 
often higher in rural areas, the government, through establishing health clinics, provided effective access to contraceptive tools and increased public awareness of the program. Contrary to common perception that religion is an impediment for FP adoption, religion did not play such a role in Iran; quite to the contrary, the evidence points to religion's important role in its success. At the time of writing, Iran has announced a new family program. An assessment and analysis of its performance are subjects for future scholarship.

\section{References}

Abbasi-Shavazi M., Mehryar A. et al., 2002, Revolution, War and Modernization: Population Policy and Fertility Change in Iran, Journal of Population Research, 19, 1, pp. 35-36.

Abbasi-Shavazi M., 2002, Recent changes and the future of fertility in Iran, United Nations. Department of Economic and Social Affairs. Population Division, New York, 2004, pp. 425-439.

Adler M. A., 1997, Social change and declines in marriage and fertility in Eastern Germany, Journal of Marriage and the Family, 59 (1), pp. 37-49.

Afshar H., 1985, Women, State and Ideology in Iran, Third World Quarterly, 7, 2.

Aghajanian A., 1998, Family Planning and Recent Fertility Trends in Iran Measure Evaluation Project, Population Center University of North Carolina, pp. 13-14.

Apud A., Mehryar H., 2005, Shi'ite Teachings. Pragmatism and Fertility Change in Iran, [in:] Jones G. W., Karim M. (eds.), Islam, the State and Population, London, p. 133.

Bongaarts J., 1978, A framework for analyzing the proximate determinants of fertility, Population and development review, pp. 105-132.

Caldwell J., 1980, Mass Education as a Determinant of the Timing of Fertility Decline, Population and Development Review, 6 (2), (Jun, 1980), pp. 225-255.

Carr D. L., Pan W. K., Bilsborrow R. E., 2006, Declining Fertility on the Frontier: The Ecuadorian Amazon, Population and Environment, 28, 1, pp. 17-39.

Carr D. L., 2007, Resource Management and Fertility in Mexico's Sian Ka'an Biosphere Reserve: Campos, Cash, and Contraception in the Lobster-fishing Village of Punta Allen, Population and Environment, 29 (2), pp. 83-101.

Carr D. L., Norman E., 2008, Global civil society? The Johannesburg World Summit on Sustainable Development, Geoforum, 39, pp. 358-371.

Coale A. J., 1986, Population trends and economic development, [in:] Menken J. (ed.), World Population and U.S. Policy: The Choices Ahead, New York, W. W. Norton, pp. 96-104.

Davis J. D., López-Carr D., 2010, The Effects of Migrant Remittances on Population-Environment Dynamics in Migrant Origin Areas: International Migration, Fertility and Consumption in Highland Guatemala, Population and Environment, 32, pp. 216-237.

Eriksson M., 2000, Reproductive freedom in the Context of International Human Rights and Humanitarian Law, Kluwer Law International.

Esfahani H., Pesaran H., 2008, Iranian Economy in the Twentieth Century: A Global Perspective, Iranian Studies, 42, 2 (2009), pp. 177-211.

Freedman L., Isaacs S., 1993, Human Rights and Reproductive choice, Studies in Family Planning, 24, 1, pp. 18-30.

Goode W. J., 1963, World revolution and family patterns, Free Press of Glencoe, New York.

Greenhalgh S., 1988, Families and Networks in Taiwan's Economic Development, [in:] Edwin A., Greenhalgh S., Greenhalgh W. (eds.), Contending Approaches to East Asian Development. 
Hoover E. M.,1958, Population Growth and Economic Development in Low-Income Countries: A Case Study of India's Prospects, Princeton, Princeton University Press.

Jafari-Mojdehi A., 2003, Imbalance in Marriage Status in Iran [Persian], Journal of Social Sciences, 5, pp. 83-104.

Kearns R. A., 1993, Place and health: towards a reformed medical geography, The Professional Geographer, 45 (2), pp. 139-147.

Kohler H., Kohler I., 2002, Fertility Decline in Russia in the Early and Mid 1990s: The Role of Economic Uncertainty and Labour Market Crises, European Journal of Population, 18, pp. 233-262.

Laresn J., 2001, Iran's Birth Rate Plummeting at Record Pace: Success Provides a Model for Other Developing Countries, Earth Policy Institute: http://www.mnforsustain.org/iran_model_of_reducing_fertility.htm

McNicoll G., 1980, Institutional determinants of fertility change, Population and Development Review, 6 (3), p. 441-462.

McNicoll G., 1985, The nature of institutional and community effects on demographic behaviour: a discussion, [in:] Casterline J. B. (ed.), The collection and analysis of community data, Voorburg, International Statistical Institute, pp. 177-184.

McNicoll G., 1994, Institutional analysis of fertility, Population Council Working Paper, 62, New York, The Population Council.

Mahmood S. T., 1977, Family planning: The Muslim viewpoint, Vikas Publishing House.

Mahmoudain H., 2005, The Increasing Age at Marriage: Examining the Protective Factors [Persian], Journal of Social Sciences, 24, pp. 27-53.

Malekafzali H., 2004, Population control and Reproductive Health in the Islamic Republic of Iran, Archives of Iranian Medicine, 7 (24), pp. 247-250.

McIntosh C., Finkle J., 1995, The Cairo Conference on Population and Development: A New Paradigm. Population Council, Population and Development Review, 21 (2), pp. 223-260.

Mehryar A., 1997, Reproductive health in The Islamic Republic of Iran: Organization and Indicators, Tehran, Institute for Research on Planning and Development.

Mehryar A., Tabibian M. et al., 1999, Poverty in Iran: Policies and Estimates, Institute for Research on Planning and Development, Tehran.

Merrick T., 2001, Population and poverty: A review of reviews, [in:] Birdsall N., Kelley A. C., Sinding S. (eds.), Population Matters: Demographic Change, Economic Growth, and Poverty in the Developing World, New York, Oxford University Press, pp. 201-212.

Moinifar H. S., 2007, Religious Leaders and Family Planning in Iran, Iran \& the Caucasus, pp. 299-313.

Moghadam V., 1988, Women, Work and Ideology in the Islamic Republic, International Journal of Middle East Studies, 20, 2, pp. 221-243.

Moore R., 2007, Family Planning in Iran, 1960-1970, [in:] Robinson W. C., Ross J. A. (eds.), In the Global Family Planning Revolution: Three Decades of Population Policies and Programs, The World Bank Washington, DC, pp. 33-58.

Omran A. R., 1992, Family Planning in the Legacy of Islam, London, 40.

Price M., Lewis M., 1993, The reinvention of cultural geography, Annals of the Association of American Geographers, 83 (1), pp. 1-17.

Reichenbach L., 2009, The Global Reproductive Health and Rights Agenda: Opportunities and Challenges for the Future, [in:] Reichenbach L., Roseman J. (eds.), Reproductive Health and Human Rights, University of Pennsylvania, pp. 21-40.

Rutkevich, M. N., 1996, Depopulyatsiya ili vymiranie? [Depopulation or extinction?], Sotsiologicheskie Issledovaniya 23 (3), pp. 104-110. 
Salehi-Isfahani D., Abbasi Shavazai M. et al., 2010, Family Planning and Fertility Decline in Rural Iran: The Impact of Rural Health Clinics, Health Economics, 19, pp. 159-180.

Shahvazi M., Morgan S. et al., 2009, Family Change and Continuity in Iran: Birth Control Use before First Pregnancy, Journal of Marriage and Family, 71, pp. 1309-1324.

Sutherland E., Carr D. L., Curtis S., 2004, Fertility and the environment in a natural resource dependent economy: Evidence from Petén, Guatemala, Población y Salud en Mesoamérica, 2 (1), pp. 1-12.

Trewartha G. T., 1953, A case for population geography, Annals of the Association of American Geographers, 43 (2), pp. 71-97.

UN, 1968, Proclamation of Tehran, http://www1.umn.edu/humanrts/instree/I2ptichr.htm

UN, 1984, Report of the international Conference on Population, 1084, Mexico City, 6-14 August 1984 (New York: UN Doc E/CONF.76/19, 1984), pp. 8-40.

UN, 1999 Statement of the Islamic Republic of Iran's Delegation, ICPD+5 International Forums, the Hague, http://www.un.org/popin/icpd/icpd5/hague/iran.htm

Witte J. C., Wagner G. G., 1995, Declining fertility in East Germany after unification: A demographic response to socioeconomic change, Population and Development Review, 21 (2), pp. 387-397. 
http://rcin.org.pl 